\title{
Factors Associated with Intimate Partner Violence: Logistic Regression Approach
}

\author{
Prativa Tiwari $^{1} \&$ Gauri Shrestha $^{2 *}$ \\ Submitted: 28 July 2018; Accepted: 06 September 2018
}

Published online: 26 September 2018

DOI: http://dx.doi.org/10.3126/njs.v2i0.21154

\begin{abstract}
Background: Intimate Partner Violence is a major health and human rights problem. Globally, intimate partner violence includes physical act of violence together with sexual coercion, physical threats, psychological abuse and controlling actions by the intimate partner.

Objective: This study aims to identify the factors influencing intimate partner violence of married women in Pokhara, Lekhnath Metropolitan City ward number 27, Kaski, Nepal.

Materials and Methods: This study is entirely based on the primary data. The sample contains 303 married women of 15-49 years selected by systematic sampling. Data was collected using structured questionnaire and face to face interview. The questionnaire used is modified version of the questionnaire designed and recommended by World Health Organization (WHO) and Program for Appropriate Technology in Health 'PATH' (2005).Data was analyzed using descriptive and inferential statistical methods. To determine the significant factors, Logistic regression model was used for establishing linkage between intimate partner violence and several explanatory variables.

Results: Fitted model showed the variables, affair with other women and alcohol consumption habit were highly significant predictors for the intimate partner violence. Occupation of husband was significant predictor for physical violence and occupation of respondent was significant for sexual violence. Goodness of fit tests (Hosmer-Lemeshow chi-square statistic, Negelkerke $R^{2}$ ) showed that all three models fit well to the proposed Logistic regression model.

Conclusion: Although violence is a multidimensional concept, this study has attempted to capture three types of violence namely psychological, physical and sexual called IPV. The IPV was collapsed to create a dichotomous variable on the basis of whether the woman has IPV or not. A number of independent variables are taken into account based on scientific literature review.
\end{abstract}

Keywords: Binary Logistic regression, Hosmer-Lemeshow chi-square statistic, intimate partner violence, , systematic sampling.

Address correspondence to the authors: Central Department of Statistics, TU, Kirtipur, Nepal Email: prativasapkota5@yahoo.com ${ }^{1}$; gaurishrestha@yahoo.com ${ }^{2 *}$ (Corresponding author email) 


\section{INTRODUCTION}

"Intimate Partner Violence" (IPV) is one of the most common forms of violence against women and includes physical, sexual, and emotional abuse and controlling behaviors by an intimate partner. In Nepal, more than 50 percentage of the population is female (Central Bureau of Statistics [CBS], 2011) but they are lagging behind men in overall aspect. Nepal is considered as a male dominated society and grounds of this domination are patriarchal society and economic dependence of women on men. Violence against women means any act of gender-based violence that results in, or is likely to result in, physical, sexual or psychological harm or suffering to women, including threats of such acts, coercion or arbitrary deprivation of liberty, whether occurring in public or in private life (United Nations [UN], 1993). According to the UN declaration physical violence includes beatings, stabbing, burning, and the intentional deprivation of food. Psychological violence includes the enforcement of strict isolation, constant denigration, and public humiliation. Sexual abuse includes sexual harassment, coerced sex and forced pregnancy. Women are at greater risk of being sexually assaulted or exploited, either in childhood, adolescence, or as adults both within family and community (World Health Organization [WHO], 2002).

Violence against women is becoming the serious public health problem because of which this issue is adversely associated with the life of women and children. Intimate partner violence against women is the most persisting form of violence and women are often in great danger in the place where they should be safest within their families. Although female to male violence occur sometime in Nepal but violence from male to female is the most common form of violence. A study conducted in Nepal showed that one third of the women in the age group 15-49 having experienced emotional, physical or sexual violence from their spouses (Ministry of Health and Population [MOHP], New ERA, \& ICF International Inc, 2012). Globally, it has been a subject of research interest since1970s but the detailed data indices is low in developing world. Gradually, IPV is considered as a legitimate human right issue as well as a significant threat to women's health and well-being. World Health Organization (WHO) multi-country study reported that 15-71 percent of women had experienced violence. According to Nepal Demographic Health Survey (NDHS) 2011, overall1/3 ${ }^{\text {rd }}$ of women of reproductive age group had ever experienced violence and $17 \%$ reported violence in past 12 months prior to the survey (MOHP, 2012). A thorough review of international publication shows that educational level, age, parity, partner's behavior and employment status are useful variables in predicting IPV, which is often taken as a private affair and the incidence of violence is mostly curtailed in family pressure. In most cases, victim prefers silence and perpetrator easily escapes. Consequently, women become more vulnerable to IPV, particularly, in poor and rural patriarchal communities like in Nepal. Therefore, study of IPV against women in Nepalese context will be very essential. 


\section{MATERIALS AND METHODS}

\section{Data and study area}

This study is entirely based on primary data. The area of study is ward number 27 of Pokhara Lekhnath Metropolitan City of Kaski district. The sampling unit is married women of age between 15 to 49 years and completed at least one year of marriage. Women having divorced and separated status were also included to get the strong reason of separating from their husband. The information about the household was taken from "TOLI" (Team Organizing Local Institution) through head office of Metropolitan. Total number of household of the selected ward was 2827 . Approximately $10 \%$ of households from target population were taken as sample size, so the sample of this study is 303 households by using systematic sampling technique. Moreover, to select eligible respondent from related household daughter in law was kept in priority and in case of more than two daughters in laws in single household one of them was chosen randomly. If the respondent of the selected household were not available, then house of consecutive number were selected. For collecting data, structured questionnaire were used and face to face interview was conducted. All the questionnaires were finalized by modifying the questionnaire which was designed and recommended by World Health Organization and 'PATH' (2005). The questionnaires were developed in English at first and then translated into Nepali language.

\section{Variables}

Dependent variable of the study is IPV i.e, psychological, physical and sexual violence. To measure the psychological violence, a set of three questions such as; insulting or make feeling bad about yourself, belittled or humiliated in front of other people and threatening to hurt were asked. Each of these questions contains two categories of responses as 'yes' and 'no'; coded as 1 and 0 , respectively. If the response was 'yes' then they were further requested to answer "had this happened once (coded as 1), sometimes (coded as 2) and frequently (coded as 3)". These coded values have been added to measure the degree of severity. The possible score varies between 1 and 9 . The severity of psychological violence has been categorized low (if the score ranges between1 to 3), moderate (4 to 6 ) and severe (7 to 9). In psychological violence, a set of six questions were asked. All these questions were coded as yes (coded 1) or no (coded 0 ). If response was yes then they were inquired on how many times it had occurred. If they occurred only one, few and many then they were coded as 1,2 and 3, respectively. The possible score of physical violence varies from 1 to 18 . As in psychological violence, it was categorized into three groups: low (score ranging from1 to 6), medium (7 to 12) and severe or high (13 to 18). Similarly, to measure the sexual violence, a set of three questions were asked to understand the situation of sexual violence among women. As previously, all the questions were designed to get dichotomous response ( $\mathrm{Yes}=1$ or No $=0$ ). If the response was yes then they were asked how many times it had occurred. They were coded 1, 2 ad 3 for the cases if it had occurred once, few and many times, respectively. The possible score of the composite value ranges from 1 to 9 . It is also 
grouped into three categories: low (1 to 3), moderate (4 to 6 ) and severe or high (7 to 9). Reliability of IPV was measured through Cornbrash's alpha. Cornbrash's alpha for the question of psychological, physical and sexual violence are 0.644, 0.796 and 0.698 , respectively which can be considered as reasonably high. For model fitting, the dependent variable IVP is taken to be dichotomous variable as no violence and violence. The violence includes low, moderate and severe violence. A number of independent variables are taken based on the scientific literature review. These variables are age of respondent, duration of marriage, type of marriage, ethnicity, marital status, religion, and education of respondent woman, occupation of respondent, and husband's affair with other women, having other wife/wives, alcohol consumption habit of husband, education of husband and occupation of husband.

\section{Data analysis}

For univariate analysis, data have been expressed in percentages and frequency distribution. Chisquare test has been performed to examine the association between selected background characteristics and outcome variable as a bivariate analysis. In this study, the dependent variable, intimate partner violence against women is recoded into dichotomous variable on the basis of response either yes or no. For multivariate analysis, logistic regression method has been used. Three logistic regression models were developed separately for psychological, physical and sexual violence to assess the influence of predictors on IVP.

$$
Y_{i}=\left\{\begin{array}{c}
1, \text { if response is yes } \\
0, \text { otherwise }
\end{array}\right.
$$

Logistic regression extended to model with multiple explanatory variables $(X)$. The model for $\pi_{\mathrm{i}}=\mathrm{P}\left(Y_{\mathrm{i}}\right.$ $=1)$ probability that $Y_{\mathrm{i}}=1$ and $1-\pi \mathrm{i}=\mathrm{P}\left(Y_{\mathrm{i}}=0\right)$ probability that $Y_{\mathrm{i}}=0$ at values $X=\left(X_{1}, X_{2}, \ldots X_{\mathrm{k}}\right)$ of $k$ predictors and the subscript $i$ denote $i^{\text {th }}$ individual and the model assumed is

$$
\pi_{i}=\frac{1}{1+e^{-\beta_{0}+\sum_{j=1}^{k} \beta_{j} X_{j}}}
$$

Then logit or $\log$ odds of having $Y_{\mathrm{i}}=1$ is modeled as a linear function of the explanatory variables, that is $\log \frac{\pi_{i}}{1-\pi_{i}}=\beta_{0}+\sum_{j=1}^{k} \beta_{j} X_{j}$

where $X \mathrm{j},(j=1,2, \ldots, k)$ are explanatory variables. $0 \leq \pi_{\mathrm{i}} \leq 1, j=0,1,2, \mathrm{k}$, and $i=1,2 \ldots, n$. Using the method of calculus, a set of values for $\beta_{0}$ and the $\beta_{\mathrm{j}}$ can be calculated that maximize Likelihood function and the resulting values are known as maximum likelihood estimates (MLE's). The adequacy of the developed model was verified through standard statistical means such as overall goodness of fit and statistical significance of estimated parameter. 


\section{RESULTS}

The percentage distribution of the dependent variables is presented in Figure 1. About 28.1 percent of respondent reported they never had psychological violence. About 5.6 percent of women have experienced severe, 21.8 percent moderate and 44.6 percent low psychological IPV. About 37.3 percent of women don't experience any type of physical violence. About 3.3 percent of women have experienced severe, 13.9 percent moderate and 45.5 percent face low physical intimate partner violence. Similarly, 34.7 percent of respondent reported they never had sexual violence and having low sexual violence. While only 4.3 percent severe and 26.4 experienced moderate intimate sexual violence.

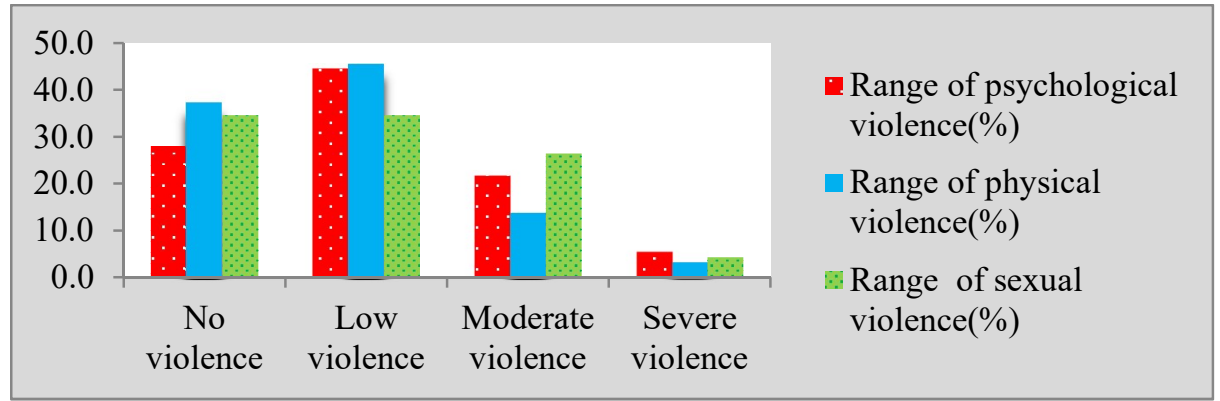

Fig.1. Proportion of respondents on the basis of IPV.

These dependent variables were made dichotomous for the further statistical analysis as no violence and violence (low + moderate + severe). It revealed that about 71.9 percent of respondent reported that they have experienced psychological violence and 62.7 percent and 65.3 percent reported that they have experienced physical and sexual violence, respectively.

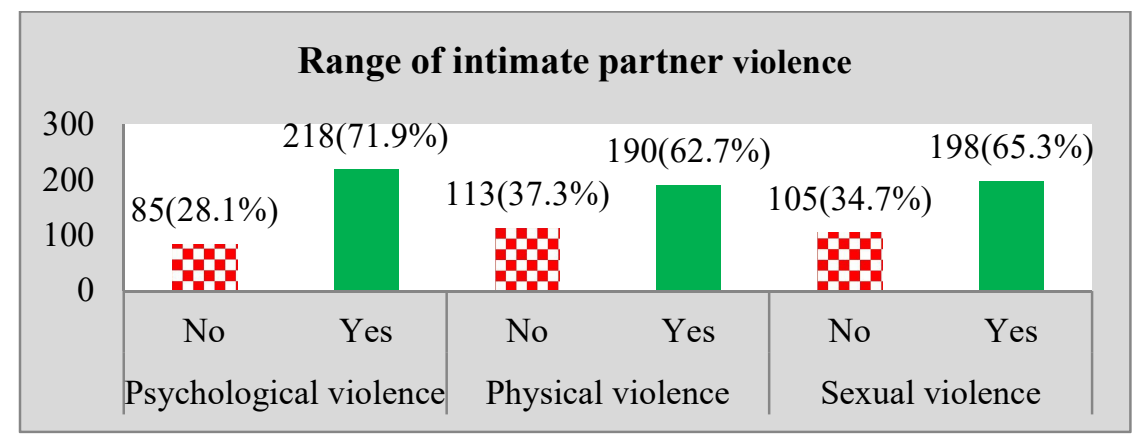

Fig. 2. Proportion of respondents on the basis of IPV as dichotomous.

For bivariate analysis, Chi- square test has been used. In bivariate analyses, an attempt has been made to explore the relationship between selected independent variable and dependent variable individually. Associations which are significant up to 5 percent level of significance have been considered as significant. Table 1 revealed that there is statistically significant relationship between age of women and psychological and physical violence $\left(\chi^{2}=3.818\right.$ with p-value $0.034 ; \chi^{2}=3.335$ with $p$ value 0.044$)$ but not significant with sexual violence $\left(\chi^{2}=0.026\right.$ with p-value 0.483$)$. It showed that there is no significant difference in having IPV on the basis of religion, duration of marriage and education of women in the study area, the $p$-value for calculated chi-square is seen to be more than 
0.05. It is seen that those women who were involved in business have less IPV compared with the women who were involved in agriculture and housewife. The $p$-value for calculated chi-square is less than 0.05 which indicates that there is a significant association between the occupation of respondent and the IPV at $5 \%$ level of significance.

Table 1. Bivariate analysis of IPV with independent variables of respondent.

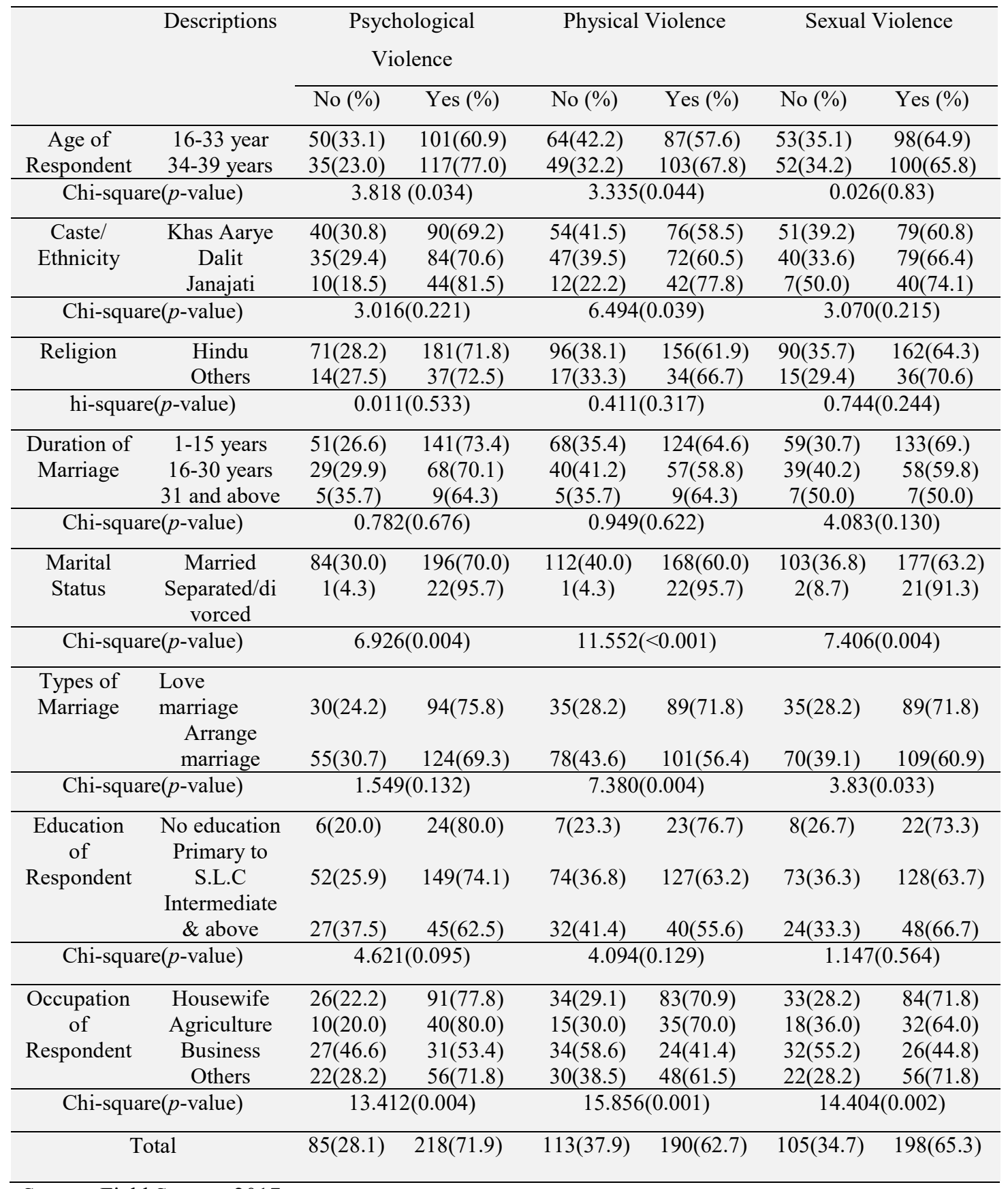

Source: Field Survey, 2017 
From the Table 2, it revealed that having other wife, Husband's offer with others, alcohol consumption has a strong significant association with IPV. Occupation of husband and education of husband are significant only with physical violence at 5 percent level of significance. It is seen that IPV is more common among women whose husband drink alcohol daily as compared with the women whose husbands doesn't take alcohol.

Table 2. Bivariate analysis of IPV with independent variables of respondent's husband.

\begin{tabular}{|c|c|c|c|c|c|c|c|}
\hline \multirow{2}{*}{ Variables } & \multirow{2}{*}{ Descriptions } & \multicolumn{2}{|c|}{ Psychological Violence } & \multicolumn{2}{|c|}{ Physical Violence } & \multicolumn{2}{|c|}{ Sexual Violence } \\
\hline & & No (\%) & Yes $(\%)$ & No $(\%)$ & & & No $(\%)$ \\
\hline \multirow{2}{*}{$\begin{array}{c}\text { Having other } \\
\text { wife/wives }\end{array}$} & No & $79(30.3)$ & $182(69.7)$ & $107(41.0)$ & $154(59.0)$ & $98(37.5)$ & $163(62.5)$ \\
\hline & Yes & $6(14.3)$ & $36(85.7)$ & $6(8.0)$ & $36(85.7)$ & $7(16.7)$ & $35(83.3)$ \\
\hline \multicolumn{2}{|c|}{ Chi-square( $p$-value $)$} & \multicolumn{2}{|c|}{$4.579(0.021)$} & \multicolumn{2}{|c|}{$11.037(<0.001)$} & \multicolumn{2}{|c|}{$6.966(0.005)$} \\
\hline \multirow{2}{*}{$\begin{array}{l}\text { Affair with } \\
\text { other women }\end{array}$} & No & $80(35.1)$ & $148(64.9)$ & $107(49.6)$ & $121(53.1)$ & $100(43.9)$ & $128(56.1)$ \\
\hline & Yes & $5(6.7)$ & $70(93.3)$ & $6(8.0)$ & $69(92.0)$ & $5(6.7)$ & $70(93.3)$ \\
\hline \multicolumn{2}{|c|}{ Chi-square( $p$-value) } & \multicolumn{2}{|c|}{$25.586(<0.001)$} & \multicolumn{2}{|c|}{$36.574(<0.001)$} & \multicolumn{2}{|c|}{$34.475(<0.001)$} \\
\hline \multirow{4}{*}{$\begin{array}{c}\text { Frequency } \\
\text { of alcohol } \\
\text { consumption }\end{array}$} & $\begin{array}{c}\text { Doesn't take } \\
\text { alcohol }\end{array}$ & $36(52.9)$ & $32(47.1)$ & $44(64.7)$ & $24(35.5)$ & $38(55.9)$ & $30(44.1)$ \\
\hline & Some times & $39(26.4)$ & $109(73.6)$ & $55(37.2)$ & $93(62.8)$ & $53(35.8)$ & $95(64.2)$ \\
\hline & Daily & $5(6.6)$ & $71(93.4)$ & $8(10.5)$ & $68(89.5)$ & $9(11.8)$ & $67(88.2)$ \\
\hline & Don't know & $5(45.5)$ & $6(54.5)$ & $6(54.5)$ & $5(45.5)$ & $5(45.5)$ & $6(54.5)$ \\
\hline \multicolumn{2}{|c|}{ Chi-square( $p$-value) } & \multicolumn{2}{|c|}{$40.096(<0.001)$} & \multicolumn{2}{|c|}{$46.536(<0.001)$} & \multicolumn{2}{|c|}{$31.650(<0.001)$} \\
\hline \multirow{5}{*}{$\begin{array}{l}\text { Occupation } \\
\text { of husband }\end{array}$} & Agriculture & $7(15.9)$ & $37(84.1)$ & $8(18.2)$ & $36(81.8)$ & $17(38.6)$ & $27(61.4)$ \\
\hline & Business & $18(26.9)$ & $49(73.1)$ & $27(40.3)$ & $40(59.7)$ & $26(38.8)$ & $41(61.2)$ \\
\hline & Service & $22(32.8)$ & $45(67.2)$ & $29(43.3)$ & $38(56.7)$ & $21(31.3)$ & $47(68.7)$ \\
\hline & Foreign & $21(35.0)$ & $39(65.0)$ & $30(50.0)$ & $30(50.0)$ & $27(45.0)$ & $33(55.0)$ \\
\hline & others & $17(26.2)$ & $48(73.8)$ & $19(29.2)$ & $46(70.8)$ & $14(21.5)$ & $51(78.5)$ \\
\hline \multicolumn{2}{|c|}{ Chi-square( $p$-value) } & \multicolumn{2}{|c|}{$5.572(0.233)$} & \multicolumn{2}{|c|}{$14.108(0.007)$} & \multicolumn{2}{|c|}{$8.916(0.063)$} \\
\hline \multirow[t]{4}{*}{$\begin{array}{c}\text { Education of } \\
\text { husband }\end{array}$} & $\begin{array}{c}\text { Up to } \\
\text { primary }\end{array}$ & $10(20.8)$ & $38(79.2)$ & $10(20.8)$ & $38(79.2)$ & $13(27.1)$ & $35(72.9)$ \\
\hline & Secondary & $4(25.3)$ & $121(74.7)$ & $59(36.4)$ & $103(63.6)$ & $56(34.6)$ & $106(65.4)$ \\
\hline & Intermediate & & & & & & \\
\hline & $\&$ above & $34(36.6)$ & $59(63.4)$ & $44(47.3)$ & $49(52.7)$ & $36(38.7)$ & $57(61.3)$ \\
\hline \multicolumn{2}{|c|}{ Chi-square( $p$-value) } & \multicolumn{2}{|c|}{$5.178(0.075)$} & \multicolumn{2}{|c|}{$9.605(0.008)$} & \multicolumn{2}{|c|}{$1.891(0.385)$} \\
\hline & & $85(28.1)$ & $218(71.9)$ & $113(37.9)$ & $190(62.7)$ & $105(34.7)$ & $198(65.3)$ \\
\hline
\end{tabular}

Source: Field Survey, 2017

\section{Logistic regression analysis of selected variables and IPV}

Out of the total respondents, 11 respondents were reported that they have no idea about the alcohol consumption habit of their husband. Due to complication in analysis these 11 respondents were excluded in the fitted model. After that sample size of the study reduced to 292. Taking IPV (psychological, physical and sexual violence) as dependent variable and the independent variables which are significant in bivariate analysis are included in logistic regression model and three models were run. 


\section{Logistic regression analysis of selected variables and intimate psychological violence}

Table 3 contains the odds ratio of logistic regression coefficients, their $p$ values, standard errors and 95 percent confidence interval for odds ratios for each category. From the fitted model, affair of husband and alcohol consumption are found to be significant to the intimate psychological violence. From the Table 3, the odds ratio of affair with other women is 3.98 which indicates that the risk of psychological violence is 3.98 times higher than those women whose husband don't have affair with another women and 95 percent confidence interval for odds ratio lies between 1.45 and 10.95 . Furthermore, alcohol consumption habit of husband is another predictor of intimate psychological violence which found to be highly significant with husbands never consuming alcohol has been taken as reference. The odds ratios for taking alcohol sometimes and daily are 3.04 and 9.49 , respectively. It means the women whose husband takes alcohol sometimes are almost 3 times likely to have intimate psychological violence compared to women whose husbands never take the alcohol. Similarly, women whose husbands consume alcohol daily are 9.5 times likely to face psychological violence compared to those of women whose husbands never take alcohol.

When only constant was included, $-2 \mathrm{LL}=342.91$ but when other variables have been included, this -2 LL has been reduced to 289.21 . This reduction tells us that the model is predicting better compared to the situation when it has only the constant included. For goodness of fit, HosmerLemeshow chi-square statistic is 6.29 with $p$ value 0.299 which implying that the model fits the data at an acceptable level. HereNegelkerke $R^{2}=0.24$ which indicates that $24 \%$ of the variation in intimate psychological violence has been explained by the covariate.

\section{Logistic regression analysis of selected variables and intimate physical violence}

Altogether three variables are found statistically significant in explaining the intimate physical violence. These variables are affair with other women, alcohol consumption and occupation of husband. According to analysis odds ratio of affair of husband with other women is 6.574 with $p$-value $<0.001$. It reveals that the risk of intimate physical violence is 6.5 times higher than those women whose husband don't have affair with another women. Furthermore, alcohol consumption habit of husband is another predictor of physical violence which found to be highly significant factor with the intimate physical violence with husbands who never take alcohol have been taken as reference, odds ratios for alcohol consumption sometimes and daily are 3.342 and 10.212, respectively. It means the women whose husband takes alcohol sometimes are almost 3 times likely to have physical violence than the women whose husband never takes the alcohol. Similarly, women whose husbands take alcohol daily are 10 times likely to face physical violence than those of women whose husbands never take alcohol. 
Table3. Fitted model for explaining the psychological violence, $\mathrm{N}=292$.

\begin{tabular}{|c|c|c|c|c|c|}
\hline \multirow[t]{2}{*}{ Explanatory Variables } & \multirow{2}{*}{$\begin{array}{l}\text { Odds } \\
\text { Ratio }\end{array}$} & \multirow[t]{2}{*}{ S.E } & \multirow[t]{2}{*}{$p$ value } & \multicolumn{2}{|c|}{$95 \%$ C.I. for OR } \\
\hline & & & & Lower Bound & Upper Bound \\
\hline \multicolumn{6}{|l|}{ Affair with other women: } \\
\hline No (R) & - & - & & - & - \\
\hline Yes & 3.982 & 0.516 & 0.007 & 1.449 & 10.947 \\
\hline \multicolumn{6}{|c|}{ Alcohol consumption habit: } \\
\hline Does not take $(\mathrm{R})$ & - & - & - & - & - \\
\hline Sometimes & 3.038 & 0.311 & $<0.001$ & 1.651 & 5.589 \\
\hline Daily & 9.486 & 0.546 & $<0.001$ & 3.255 & 27.646 \\
\hline Constant & 10.133 & 0.853 & 0.007 & & \\
\hline \multicolumn{6}{|c|}{ OR $=$ Odds Ratio, $\mathrm{R}=$ Reference, $\mathrm{S} . \mathrm{E}=$ Standard error, C.I = Confidence interval } \\
\hline Degree of freedom & 3 & \multicolumn{2}{|c|}{ Initial -2loglikelihoo } & \multicolumn{2}{|c|}{342.908} \\
\hline Hosmer and Lemeshow & 0.299 & \multicolumn{2}{|c|}{ Final -2loglikelihoor } & \multicolumn{2}{|c|}{289.206} \\
\hline Nagelkerke $R^{2}$ & & \multicolumn{4}{|l|}{0.243} \\
\hline
\end{tabular}

Occupation of husband shows strong relation with the prevalence of intimate physical violence. Here agriculture is taken as the reference for the occupation of husband. The odds ratio for the business 0.291 reveals that those women whose husband occupation is business have 71percent less chance of having physical violence compared with women whose husbands were involved in agriculture. Similarly, odds ratio for service and foreign employed are 0.320 and 0.217 , which indicates that women whose husbands choose service as occupation is 68 percent less likely to suffer from physical violence than the women from reference group. The women from the group whose husbands had work in foreign have 78 percent less chance of getting physical violence than the women whose husbands were involved in agriculture. The last category of husband occupation labeled as 'Other' includes students, labor and pensioners. This group has odds ratio of 0.20 which reveals that wife of this group have 80 percent less chance of physical violence than the reference group.

The final -2LL value has been lowered from initial -2LL 383.71 to 306.03 . This reduction tells us that the model fit well. We observed from the table 4, that the Hosmer-Lemeshow chi-square statistic is 7.90 with $p$ value 0.698 and Negelkerke $R^{2}=0.319$. 
Table 4. Fitted model for explaining the intimate physical violence, $\mathrm{N}=292$.

\begin{tabular}{|c|c|c|c|c|c|}
\hline \multirow[t]{2}{*}{ Explanatory Variables } & \multirow{2}{*}{$\begin{array}{l}\text { Odds } \\
\text { Ratio }\end{array}$} & \multirow[t]{2}{*}{ S.E } & \multirow[t]{2}{*}{$p$ value } & \multicolumn{2}{|c|}{ 95\% C.I. for OR } \\
\hline & & & & Lower Bound & Upper Bound \\
\hline \multicolumn{6}{|l|}{ Affair with other women } \\
\hline No $(\mathrm{R})$ & - & - & & - & - \\
\hline Yes & 6.574 & .489 & $<0.001$ & 2.523 & 17.131 \\
\hline \multicolumn{6}{|c|}{ Alcohol consumption habit } \\
\hline Does not take (R) & - & - & - & - & - \\
\hline Sometimes & 3.342 & 0.327 & $<0.001$ & 1.761 & 6.344 \\
\hline Daily & 10.211 & 0.522 & $<0.001$ & 3.667 & 28.432 \\
\hline \multicolumn{6}{|l|}{ Occupation of husband } \\
\hline Agriculture(R) & - & - & - & - & - \\
\hline Business & 0.291 & 0.521 & 0.018 & 0.105 & 0.809 \\
\hline Service & 0.320 & 0.510 & 0.025 & 0.118 & 0.869 \\
\hline Foreign & 0.217 & 0.524 & 0.004 & 0.078 & 0.607 \\
\hline others & 0208 & 0.586 & 0.007 & 0.066 & 0.657 \\
\hline Constant & 2.317 & 0.712 & 0.231 & & \\
\hline \multicolumn{6}{|c|}{$\mathrm{OR}=$ Odds Ratio, $\mathrm{R}=$ Reference, $\mathrm{S} . \mathrm{E}=$ Standard error, $\mathrm{C} . \mathrm{I}=$ Confidence interval } \\
\hline Degree of freedom & 7 & \multicolumn{2}{|c|}{ Initial -2loglikelihoo } & \multicolumn{2}{|c|}{383.707} \\
\hline Hosmer and Lemeshow & 0.698 & \multicolumn{2}{|c|}{ Final -2loglikelihoo } & \multicolumn{2}{|c|}{306.302} \\
\hline Nagelkerke $R^{2}$ & & \multicolumn{4}{|l|}{0.319} \\
\hline
\end{tabular}

Table 5 showed the standard errors, odds ratios and the 95 percent confidence interval. Affair with other women and alcohol consumption habit are positively associated whereas occupation of respondent are negatively associated with the dependent variable in the fitted model. The corresponding values of odds ratios revealed the following important results on intimate sexual violence when values of predictor variables are changed from one level to another. As housewife is taken as the reference group for the occupation of respondent, the odds ratio of business is 0.363 with lower and upper bound 0.174 and 0.755 , respectively. It reveals that those women whose occupation is business have $63 \%$ less chance of intimate sexual violence compared with the women who were housewife. Another significant factor is affair of husband with other women. According to analysis odds ratio is 7.359 with $p$-value $<0.001$. This odds ratio revels that the risk of sexual violence is 7.3 times higher than those women whose husbands don't have affair with another women. Furthermore, alcohol consumption habit of husband is another predictor of sexual violence which found to be highly significant factor with the intimate sexual violence with husbands never consuming alcohol have been taken as reference, the odds ratio for taking alcohol sometimes and daily are 2.434 and 4.250, respectively. It means the women whose husbands consume alcohol sometimes are almost 2.4 times likely to have sexual violence than 
women whose husbands never takes the alcohol. Similarly, women whose husbands consume alcohol daily are 4 times likely to face sexual violence than women at reference group.

In this model, also the final -2LL (311.86) is lower than initial -2LL (375.31). The $p$ value for Hosmer and Lemeshow statistic is 0.674 and Negelkerke $R^{2}=0.27$ which indicates that $27 \%$ of the variation in sexual violence has been explained by the predictors.

Table 5. Fitted model for explaining the intimate sexual violence, $\mathrm{N}=292$.

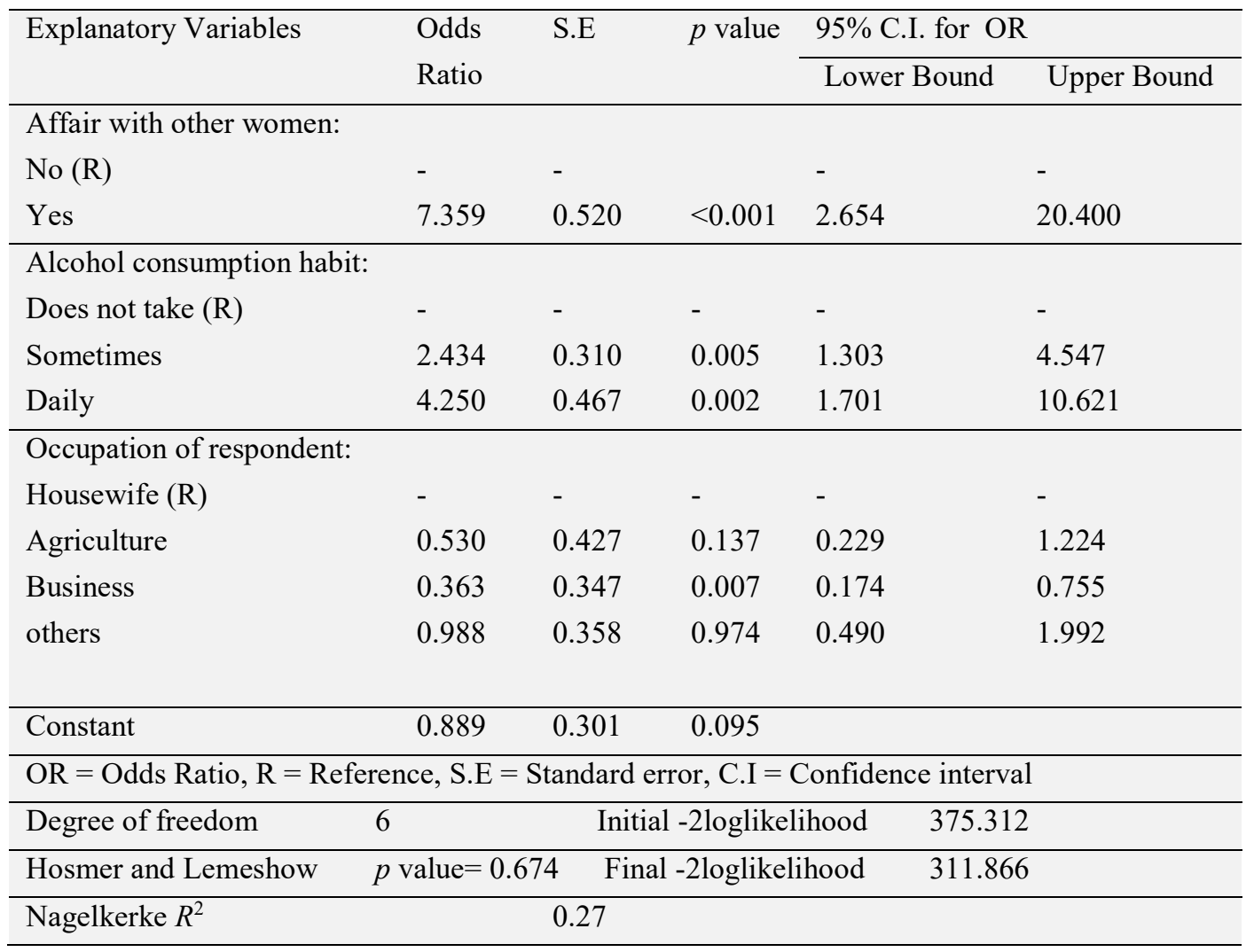

Table 6 shows the odds ratio of predictor variables (which is common in all types of violence) with different types of IPV. Results reveal that odds of physical and sexual violence were high compared psychological violence for the women whose husband have affair with other women. Here, another independent variable is alcohol consumption habit of husband which is significant in all types of violence. Regarding sexual violence, there is high proportion of women having chance of experiencing psychological and physical violence whose husbands drink alcohol daily. Almost equal percent of women had the chance of all type of violence whose husbands drink alcohol sometimes where women whose husbands doesn't take alcohol were taken as reference group. 
Table 6. Different scenario of intimate partner violence on the basis of odds ratio.

\begin{tabular}{llll}
\hline Explanatory Variables & \multicolumn{2}{l}{ Odds Ratio } & \\
\cline { 2 - 4 } & Psychological violence & Physical violence & Sexual violence \\
\hline Affair with other women: & - & - & \\
No (R) & 3.982 & 6.574 & 7.359 \\
Yes & - & & - \\
\hline Alcohol consumption habit: & & - & 2.434 \\
Does not take (R) & 3.038 & 3.342 & 4.250 \\
Sometimes & 9.468 & 10.211 & \\
Daily & & & \\
\hline
\end{tabular}

\section{DISCUSSION}

Present study was conducted with an objective to assess the determinants of intimate partner violence and its associated explanatory variables. Quantitative (bivariate and multivariate) analyses show that experience of intimate partner violence is primarily associated with intimate partner's characteristics than women's characteristics. Partner's habit of alcohol consumption and affair with other women are positively associated with IPV. The result of the study is also supported by various studies in the world.

Discussion on the study findings based on the results of estimation of the logistic regression model follows. Finally, two variables (affair with other women and alcohol consumption habit) have been found as the most influential variables on IPV. Occupation of husband also has been found as one of the influential variables on sexual violence and occupation of respondent has been found as the influential variables on sexual violence. This finding is consistent with many previous studies that showed affair with other women, occupation of husband, alcohol consumption habit were significantly associated with at least one type of IPV where $43.9 \%$ physically, $51.7 \%$ sexually and $61.7 \%$ were psychologically abused by their partner/husband (Khatri, 2013; Barkat, \& Majid, 2003). Similarly, a study made by MOHP on gender based violence in three districts of Nepal reveals that more than 21.0 percent of women were emotionally abused, 15.0 percent experienced physical violence and 16.0 percent experienced sexual violence by intimate partners. Overall, more than 27.0 percent of women had experienced at least one form of intimate partner violence. This study further reveals that violence is significantly varied with education of partners, alcohol consumption habit and multiple wives of husband (MOHP, 2012).

In a survey of women of reproductive age in rural Uganda, found male partner's alcohol consumption and their perceived HIV risk as being two important factors of IPV (Schuler, Lenzi, 
Nazneen' \& Bates, 2012). Several studies at the global level reveal that occupation of respondent is significantly associated with intimate partner violence. The likelihood of sexual violence is likely to be lower among women whose occupation is business $(\mathrm{OR}=0.363)$ compared to housewife (Schuler, 2007; Schuler et al., 2012). A thorough review of literatures revealed that a few comprehensive studies have been conducted in Nepal on IPV. In a study by World Health Organization [WHO] (2007), about half of the married women in Nepal reported ever experiencing sexual violence which is less than this study (sexual violence $=65.3$ percent). A higher number of women from the Tharu community compared with the Brahmin/Chhetri community reported ever experiencing sexual violence but this study showed that there is no significant association between the caste/ethnicity and IPV (psychological and sexual violence) but there is association between cast/ethnicity and physical violence at 5 percent level of significance. The nature of sexual violence ranged from unwanted physical touch to forced sex (WHO, 2007).

A cross-sectional study, conducted in 2009 among 1,296 young married women aged 15-24 years found more than half the women (51.9 percent) having experience of some form of violence in their lifetime. One-fourth (25.3 percent) reported physical violence and nearly half (46.2 percent) reported sexual violence. Likewise, just more than one-third (35.8 percent) of women reported experience of some form of violence in the past 12 months. No or little inter spousal communication and low autonomy of women significantly increases the odds of experiencing violence among married women (Lamichhane, Puri, Tamang, \& Dulal, 2011). A nationally representative sample of Nepal Demographic Health Survey (NDHS), 2011 revealed that more than 22.0 percent of women age 15-49 experience physical violence, while 12.0 percent at the same age group experience sexual violence at least once since age 15. Among the ever married women who experience intimate partner violence in the last 12 months, more than 40.0 percent face physical injuries. Among the forms of spousal violence, more than 23.0 percent ever experience physical, 14.3 percent ever experience sexual, 16.4 percent emotional violence in the 12 months preceding the survey (MOHP, 2012). This study showed higher percentage (71.9 percent of psychological violence, 62.7 percent of physical violence and 65.3 percent of sexual violence) of IPV as compared to report of NDHS 2011.

\section{CONCLUSION}

Although violence is a multidimensional concept, this study has attempted to capture three types of violence namely psychological, physical and sexual called IPV. The IPV variables were collapsed to create a dichotomous variable on the basis of whether the woman has IPV or not. A number of independent variables are taken into account based on scientific literature review. All the information obtained from face to face interview were entered into SPSS and analyzed. In analyzing data, univariate, 
bi-variate and multivariate analysis were employed. In this study, Logistic regression model was used to assess the influence of predictors on IPV. Affair with other women, alcohol consumption habit, occupation of respondent and occupation of husband were highly significant predictors for the IPV.

Considering model adequacy test such as goodness of fit tests (Hosmer-Lemeshow chi-square statistic,), showed that all three models fit well to the proposed Logistic regression model. Comparing the values of odds ratio obtained from psychological, physical and sexual violence, it is found that the odds of physical and sexual violence were high with compare of psychological violence for the women whose husbands have affair with other women. Here, another independent variable is alcohol consumption habit of husband which is significant in all type of violence. Almost equal percent of women had the chance of all types of violence whose husband drink alcohol sometimes where the women whose husbands doesn't take alcohol were taken as reference group.

\section{CONFLICT OF INTEREST}

The authors confirm that this article content has no conflict of interest.

\section{ACKNOWLEDGEMENTS}

Authors would like to thank Prof. Dr. Shankar Prasad Khanal, Head, Central Department of Statistics, TU and Prof. Dr. Srijan Lal Shrestha for their suggestions in preparing this manuscript and also like to show our gratitude to all those who provided support to complete this work.

\section{REFERENCES}

Barkat, A., \& Murtaza, M. (2003). Adolescent Reproductive Health in Bangladesh: Status, Policies, Programs, and Issues. Dhaka: Policy Project. Retrieve from http://www.policyproject.com/pubs/countryreports/arh_bangladesh.pdf

Central Bureau of Statistics (CBS). (2011).Preliminary Results of National Population Census 2011. Kathmandu: Central Bureau of Statistics. Retrieve from https://www.google.com.np/search?q=).+Preliminary+Results+of+National+Population+Ce nsus $+2011 .+$ Kathmandu

Khatri, D. (2013).Determinants of Intimate Partner Violence against women in Pokhara, Nepal. Abstract retrieved from http://soscbaha.org/category/conference/abstract-2013

Lamichhane, P., Puri, M., Tamang, J., Dulal, B. (2011). Women's status and violence against young married women in rural Nepal. BMC Women's Health 11:19. doi:10.1186/1472-6874-11-19

Ministry of Health and Population (MoHP) and South Asian Institute of Policy Analysis (SAIPAL) (2012).Gender based violence in Nepal: Types, Level and Prevention. 
Ministry of Health and Population (MOHP) [Nepal], New ERA, and ICF International Inc. (2012) Nepal Demographic and Health Survey 2011. Kathmandu, Nepal. Retrieve from https://www.google.com.np/search?q=nepal+demographic+and+health+survey+2011\&oq= Nepal+Demographic+and+Health+Survey+2011\&aqs

Schuler, S. R. (2007). Rural Bangladesh: sound policies, evolving gender norms and family strategies. In Maureen, A, Lewis and Marlaine E. Lockheed (eds). Exclusion, Gender and education: case studies from developing world. Washington, DC. Center for Global Development.179203. Retrieve from www.cgdev.org/sites/default/files/9781933286228-Lewis-Lockheedexclusion.pdf.

Schuler, S. R., Lenzi, R., Nazneen, S. \& Bates, L. M. (2012). Perceived decline in intimate partner violence against women in Bangladesh: Qualitative evidence. Studies in Family Planning, 44 (3): 243-257.

United Nations (UN). (1993). Strategies for confronting domestic violence: a resource manual. Vienna: Centre for Social Development and Humanitarian Affairs. Retrieve from https://www.unodc.org/pdf/youthnet/tools_strategy_english_domestic_violence.pdf

United Nations (UN). (2007). Violence against Women: harmful traditional and cultural practices in the Asian and Pacific region. Bangkok: United Nations Conference Center. Retrieve from https://www.unodc.org/pdf/youthnet/tools_strategy_english_domestic_violence.pdf

World Health Organization (WHO) and PATH. (2005). Researching Violence against Women: A Practical Guide for Researchers and Activists. Washington DC: World Health Organization and PATH.

World Health Organization (WHO). (2002). Facts on Intimate Partner Violence. Retrieve from http://www.who.int/violence_injury_prevention/violence/worldreport/factsheets/en/ipv.

World Health Organization (WHO). (2007). Perspectives on sexual violence during early years of marriage in Nepal: findings from a qualitative study. Geneva: World Health Organization. Retrieved from www.who.int/reproductive_health/publications/violence/rho_hrp_09_01/en

Reference to this paper should be made as follows:

Tiwari, P., \& Shrestha, G. (2018). Factors associated with intimate partner violence: Logistic regression approach. Nep. J. Stat., 2, 37-52. 
